\title{
An effective evolutionary algorithm for protein folding on 3D FCC HP model by lattice rotation and generalized move sets
}

Jyh-Jong Tsay ${ }^{*+}$, Shih-Chieh Su ${ }^{*+}$

From IEEE International Conference on Bioinformatics and Biomedicine 2012

Philadelphia, PA, USA. 4-7 October 2012

\begin{abstract}
Background: Proteins are essential biological molecules which play vital roles in nearly all biological processes. It is the tertiary structure of a protein that determines its functions. Therefore the prediction of a protein's tertiary structure based on its primary amino acid sequence has long been the most important and challenging subject in biochemistry, molecular biology and biophysics. In the past, the HP lattice model was one of the $\boldsymbol{a} \boldsymbol{b}$ initio methods that many researchers used to forecast the protein structure. Although these kinds of simplified methods could not achieve high resolution, they provided a macrocosm-optimized protein structure. The model has been employed to investigate general principles of protein folding, and plays an important role in the prediction of protein structures.
\end{abstract}

Methods: In this paper, we present an improved evolutionary algorithm for the protein folding problem. We study the problem on the 3D FCC lattice HP model which has been widely used in previous research. Our focus is to develop evolutionary algorithms (EA) which are robust, easy to implement and can handle various energy functions. We propose to combine three different local search methods, including lattice rotation for crossover, Ksite move for mutation, and generalized pull move; these form our key components to improve previous EA-based approaches.

Results: We have carried out experiments over several data sets which were used in previous research. The results of the experiments show that our approach is able to find optimal conformations which were not found by previous EA-based approaches.

Conclusions: We have investigated the geometric properties of the 3D FCC lattice and developed several local search techniques to improve traditional EA-based approaches to the protein folding problem. It is known that EA-based approaches are robust and can handle arbitrary energy functions. Our results further show that by extensive development of local searches, EA can also be very effective for finding optimal conformations on the 3D FCC HP model. Furthermore, the local searches developed in this paper can be integrated with other approaches such as the Monte Carlo and Tabu searches to improve their performance.

\footnotetext{
* Correspondence: tsay@cs.ccu.edu.tw; ssc95p@cs.ccu.edu.tw

+ Contributed equally

Department of Computer Science and Information Engineering, National

Chung Cheng University, 168 University Road, Minhsiung Township, Chiayi

County 62102, Taiwan
} 


\section{Background}

Proteins are essential biological molecules which play vital roles in nearly all biological processes. It is the tertiary structure of a protein that determines its functions [1-3]. Therefore the prediction of a protein's tertiary structure based on its primary amino acid sequence has long been the most important and challenging subject in biochemistry, molecular biology and biophysics. Although the interaction between individual atoms can be calculated to model the folding of a protein in a search of the tertiary structure at the lowest free energy, the massive degree of computational complexity makes this approach infeasible. As a result, researchers have proposed to develop simplified models to reduce the computational complexity in modelling protein $3 \mathrm{D}$ structure.

Lau and Dill [4] proposed a simple Hydrophobic-Polar model (HP model) based on the hydrophobic interaction between amino acids which has greatly reduced the complexity involved in protein structure prediction. The HP model has thus been used by many researchers and has been applied in various lattice algorithms [5] such as 2D Square [4,6-14], 2D Triangular [15-18], 3D Cubic $[13,19,20], 3 \mathrm{D}$ Triangular [21] and 3D Face-Centered Cubic (FCC) [22-28] lattices. Although algorithms on simplified HP lattice methods did not achieve high resolution, they provided a macrocosm-optimized protein structure. The model has been employed to investigate general principles of protein folding as well as to predict protein tertiary and quaternary structure.

Although the HP lattice model has greatly reduced the complexity of the protein folding problem, it is still NPhard [29-31]. The evolutionary algorithm is one of the major methods used to investigate protein folding. It is so far the most widely used approach in protein folding simulation [32]. Unger and Moult [14] presented a pioneering work which proposed the first Genetic Algorithm (GA) developed from Evolutionary Programming to solve protein folding problem in the 2D HP model. Their work has had a wide impact in the early progress of computational protein folding. Later, Jiang et al., [11] combined GA with the Tabu search and demonstrated that combinatorial genetic algorithms performs better than a single GA. Recently, Hoque et al., [7,22] proposed a twin-removal strategy to maintain the diversity of chromosomes to improve the performance of GA.

Various local search methods have been proposed to improve the search performance of evolutionary algorithms. Most of them are based on the concept of Move Set $[7,10,11,15,20,22,33]$. Dill et al. [34] proposed ThreeBead and End Flip for single-point move and Crankshaft for double-point move. Lesh et al., [12] developed Pull Move, and showed that Pull Move is a very effective local search method. Thachuk et al., [20] proposed End Move, Corner Move [35] and Crankshaft Move [36] to compensate for the disadvantages of Pull Move. It was shown that their approach performed better than the most advanced Ant Colony Optimisation (ACO) [13] and pruned-enriched Rosenbluth method (PERM) [37] on 2D square and 3D cubic models. Hoque et al., [7,22] also used similar local search strategies in GA such as Pull Move, Diagonal Move and Tile Move. Sali et al. [38] and Mann et al., [39] proposed a K-local move that can give sufficient structural changes within a successive interval of fixed length K. Huang et al. [10] proposed a Genetic algorithm based on optimal secondary structures (GAOSS) in which the authors designed three types of $2 \mathrm{D}$ structural motifs in the $2 \mathrm{D}$ square lattice model to improve the efficiency and increase the search capacity. The approach of Huang et al., involves a move set method based on special motifs.

Rotation is another transformation which has been proposed by Unger and Moult [14] to increase the successful rate of crossovers and mutations. However, rotation has been mainly applied to structures such as square and Triangular [17] lattices, but less explored in other lattice structures, including FCC lattices. This may be partly because how to perform rotation in them is not as clear as in cubic lattices.

In this paper, we propose to study the effect of lattice rotation in search of optimal conformations on lattice models. We focus on 3D FCC lattice which gives higher degree of freedom and does not involve the parity problem appearing in cubic lattice [21]. This model has the highest packing density [40] and can render conformations closer to the real or high resolution folding [41]. We aim to develop effective EA-based approaches which combine lattice rotations and move set operations. We have proposed three different local search methods, including lattice rotation for crossover, $\mathrm{K}$-site move for mutation, and generalized Pull Move. These three methods form our key components to improve EA-based approaches. Experiment shows that our approach performs better than previous EA-based approaches. In addition, our approach does not rely on any specific form of mathematical optimization so that it is robust and can handle arbitrary energy functions and be integrated with other approaches such as Monte Carlo and Tabu search to improve their performance.

It should be noted that, to this date, constraint programming $(\mathrm{CP})[23,24,27]$ is the state-of-the-art method which performs best for protein folding on HP lattice model [28]. This approach can ensure the solution to be the global optimum. However, from our experience with HPstruct $[23,24]$ which is an excellent tool based on constraint programming, CP-based approaches do not 
always converge to return optimal conformations. In addition, it is difficult, if not impossible, to modify CPbased approaches to handle complex energy functions efficiently, such as energy functions of pairwise interactions among all 20 amino acids [33,42,43]. On the contrary, EA-based approaches are robust and not constrained by any specific form of energy function. Although experiment shows that CP-based approaches such as HPstruct achieve the best performance [23,24], provided they converge, we still need complementary methods such as EA-based approaches to compensate for their disadvantages, especially when they fail to converge.

The remainder of this paper is organized as follows. Section 2 describes preliminaries, and reviews the HP model and 3D FCC lattice. Section 3 presents the proposed approaches, and gives details for main components of our algorithm, including rotation-based crossover, K-site-move-based mutation and generalized Pull Move. Section 4 explains the experimental results. Section 5 concludes and discusses future work.

\section{Preliminaries}

In this section, we review the HP model, 3D FCC lattice and fitness function which are used in our approach.

\section{HP model}

The HP lattice model is the most frequently used simplified model and is based on the observation that the hydrophobic interaction between the amino acid residues is the driving force for the protein folding and for the development of native state in proteins [4]. In this model, a protein is represented as a linear chain of $n$ amino acids. Each amino acid is classified based on its hydrophobic characteristics as an $\mathrm{H}$ (hydrophobic or nonpolar) or a P (hydrophilic or polar). The HP lattice model allows a chain conformation to be represented as a selfavoiding walk (SAW) on the lattice path favouring an energy-free state due to $\mathrm{HH}$ interaction. $\mathrm{HH}$ interaction in this study refers to 'topological neighbours' and not to the 'connected neighbours' as in the above mentioned chain. Figure 1 gives a conformation on a 3D FCC lattice for protein 1CNL with HP-sequence "PHНPPPPHPHPH". The number of $\mathrm{HH}$ contacts in Figure 1(b) is 7.

\section{D FCC lattice}

Raghunathan and Jernigan made an effort in 1997 to find and define a basic unit for the 3D arrangement surrounding one amino acid [40]. Consequently, a 3D FCC model was proposed and developed as shown in Figure 2 . This model can produce a nearly perfect angular distribution for the amino acids and therefore can be used directly to generate amino acid chains. In this model there are 8 cubes with 14 faces and 12 vertices, which is a unique convex polyhedral containing regular polygons, triangles and squares. As a result, every lattice point will have 12 neighbours.

In a FCC lattice, we can define the domain as the set of points $(x, y, z) \in Z$ so that $x+y+z$ is even. Two FCC points $p_{i}=\left(x_{i}, y_{i}, z_{i}\right)$ and $p_{j}=\left(x_{j}, y_{j}, z_{j}\right)$ are adjacent if and only if $\left|x_{i}-x_{j}\right| \leq 1,\left|y_{i}-y_{j}\right| \leq 1,\left|z_{i}-z_{j}\right| \leq 1$ and $\left|x_{i}-x_{j}\right|+\left|y_{i}-y_{j}\right|+\left|z_{i}-z_{j}\right|=2$ [33]. Each FCC lattice point is adjacent to 12 neighbouring points, and three consecutive adjacent points form one of these four angles $60^{\circ}, 90^{\circ}, 120^{\circ}$ and $180^{\circ}$. In this paper, the 12 neighbours of each lattice point are labelled as numbers from 1 to 12 , where 1 is for $F L(+1,+1,0), 2$ for $F R(+1,-$ 1,0), 3 for $F U(-1,+1,0)$, 4 for $F D(-1,-1,0), 5$ for $B L(+1,0$, $+1), 6$ for $B R(+1,0,+1), 7$ for $B U(-1,0,+1), 8$ for $B D(-1$, $+0,-1), 9$ for $L U(+0,+1,+1), 10$ for $L D(+0,+1,-1), 11$ for $R U(+0,-1,+1)$, and 12 for $R D(+0,-1,-1)$. Symbols $F L, F R$, $F U, F D, B L, B R, B U, B D, L U, L D, R U$ and $R D$ are used to denote fold directions with $F L$ for front-left, $F R$ for front-right, $F U$ for front-up, $F D$ for front-down, $B L$ for back-left, $B R$ for back-right, $B U$ for back-up, $B D$ for

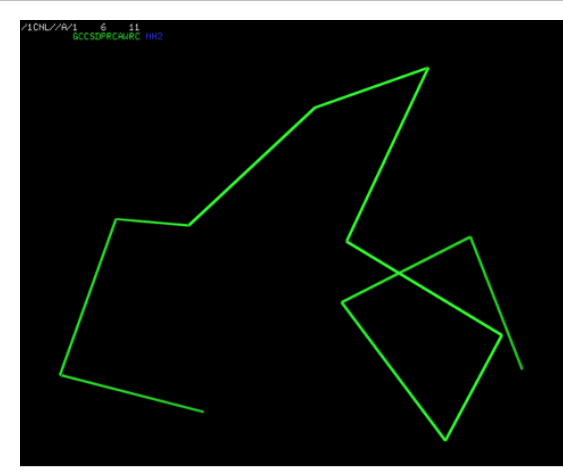

(a)

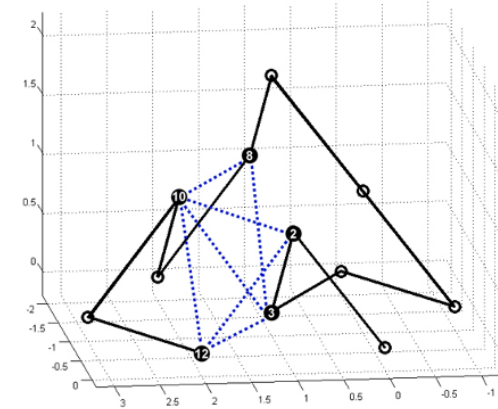

(b)

Figure 1 A ground-state conformation in the 3D FCC HP model. An example on HP lattice model: (a) The native state of the protein with PDB id 1CNL, (b) an optimal HP conformation for 1CNL on 3D FCC lattice with $7 \mathrm{HH}$ contacts denoted by dashed blue lines. 


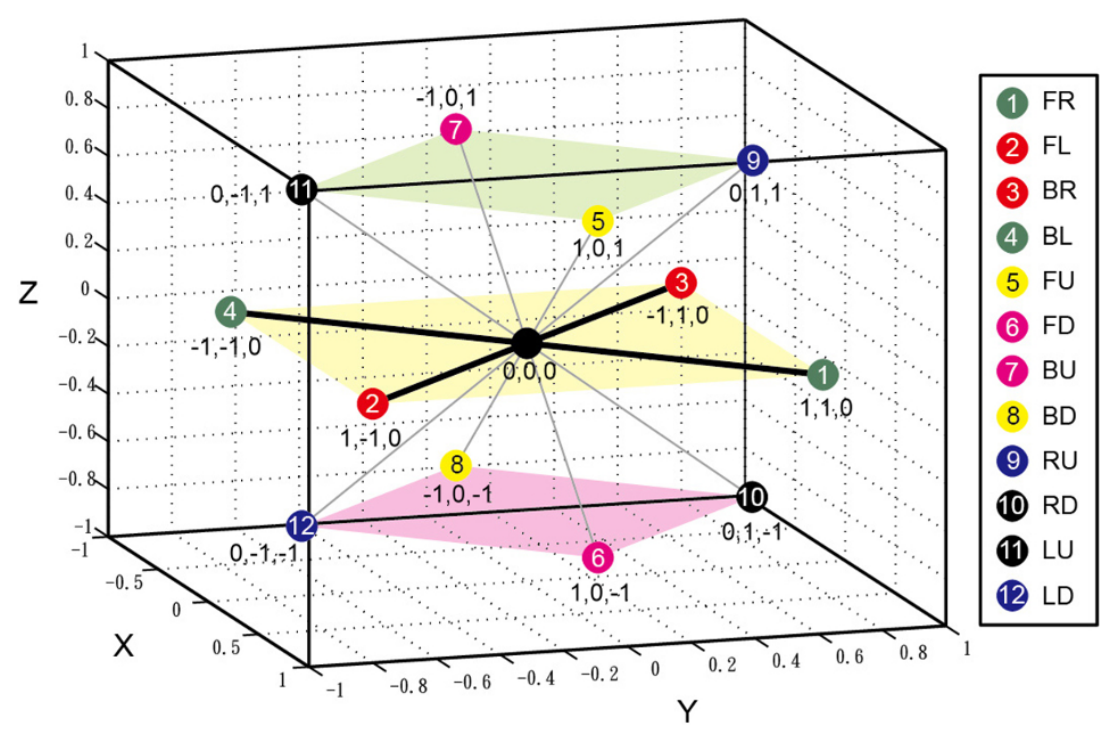

Figure 2 The FCC lattice model: each lattice point has 12 neighbours

back-down, $L U$ for left-up, $L D$ for left-down, $R U$ for right-up and $R D$ for right-down. The vector following each symbol is its corresponding direction vector.

A conformation is a sequence of adjacent points in the lattice and can be encoded as a sequence of numbers from 1 to 12. Two hydrophobic amino acids $x_{i}$ and $x_{j}$ and in lattice positions $p_{i}$ and $p_{j}$ respectively are said to be in $H H$ contact, that is $\operatorname{contact}\left(p_{i}, p_{j}\right)=1$, if and only if they are adjacent in the lattice, but not if they are adjacent in the primary sequence where $x_{i}-x_{j}|+| y_{i}-$ $y_{j}|+| z_{i}-z_{j} \mid=2$ and $|i-j|>1$. A conformation is valid if it consists of a self-avoiding walk (SAW) in the lattice: that is where $p_{i} \neq p_{j}$ for $i \neq j$. Otherwise, it is invalid.

\section{Fitness function}

Assume each $\mathrm{HH}$ contact contributes energy -1 to the conformation. The free energy of a protein conformation is defined as the negative sum of its $\mathrm{HH}$ contacts as follows. Let $s=s_{1} s_{2} \ldots s_{n}$ be an HP sequence, and $\mathrm{c}=p_{1} p_{2} \ldots p_{n}$ be a valid conformation for $s$. Then the free energy $E(c)$ of $c$ is defined as follows:

$$
E(c)=\sum_{i=1}^{n-2} \sum_{j=i+2}^{n} \operatorname{contact}\left(p_{i}, p_{j}\right)
$$

Hence, the problem of protein folding is formulated as an optimization problem which aims to find the conformation with minimal free energy. That is to find $c^{*} \in C$ (s) such that $E\left(c^{\prime \prime}\right)=\min \{E(c) \mid c \in C\}$, where $C(s)$ is the set of all valid conformations for $s$ [13].

\section{The proposed method}

In this section we present the proposed EA-based approach. Figure 3 shows the main step. To improve the search performance, the proposed approach enhances crossover by lattice rotation, Pull Move by generalized Pull Move and mutation by K-site move. We next explain details of each main step.

\section{Initialization}

An initial population was generated randomly from an $n$ - 1 dimensional space within a fixed range. We apply Depth-first search $[6,8]$ to generate random conformations. Each chromosome in the population needs to be evaluated for its fitness value as defined in equation (1). Our objective is to minimize the fitness value; that is, to maximize the number of $\mathrm{HH}$ contacts. The evaluated chromosomes were sorted according to their fitness values. This sorted population served as the basis of subsequent reproduction processes.

\section{Parent selection}

Parent selection is the process of collecting chromosomes to be selected as parents for crossover. We apply the tournament selection method in which the better of two randomly selected chromosomes is selected as one parent.

\section{Rotation-based crossover}

Crossover is a process of taking two parent conformations and producing child conformations from them. Several different crossover methods have been proposed. We use the simplest 1-point crossover in which a single crossover point on both parents' conformations is selected, and all data beyond that point in either conformation are swapped between the two parent conformations. The resulting two conformations are the children. 


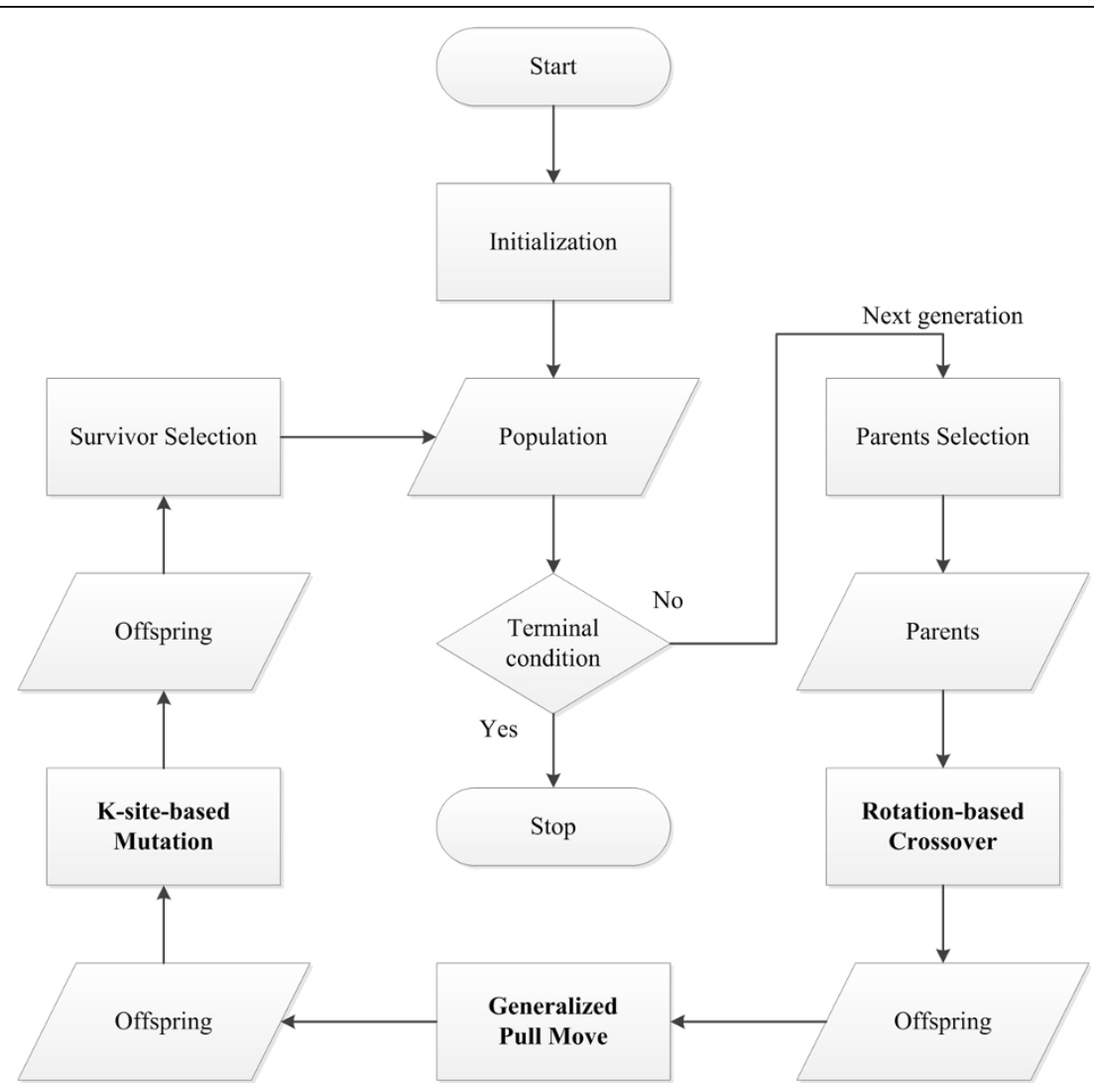

Figure 3 Main steps of the proposed EA-based approach.

However, crossover may fail to produce legal child conformations as child conformations may violate the SAW constraint, i.e. points in a child conformation may overlap. In order to increase the successful rate of crossover, we develop a rotation-based crossover in which parts from parent conformations are rotated at various angles to produce child conformations. Notice that rotationbased crossover was first proposed by Unger and Moult [14] on 2D square lattice. In this paper, we apply it to 3D FCC lattice model. We investigate the geometric structure of 3D FCC lattice, and identify several valid rotations which keep all rotated points fully overlapped with the original points in the lattice, and can be performed by simple neighbour permutations. In particular, we identified 17 rotations which are classified into two types, square-based and triangle-hexagon-based. Thus, each rotation-based crossover will generate at most 17 new chromosomes. Each rotation is performed by first partitioning all lattice points into parallel planes, and then rotating all planes synchronously.

In square-based rotation, the neighbours of the central point are partitioned into squares. Figure 4 shows 3

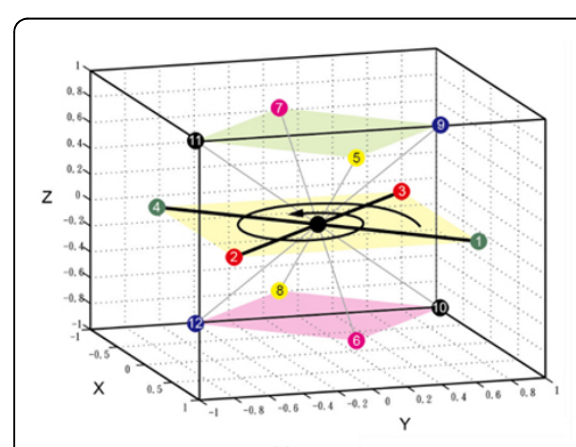

(a)

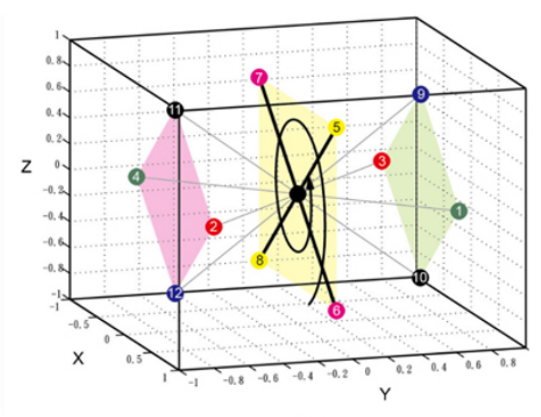

(b)

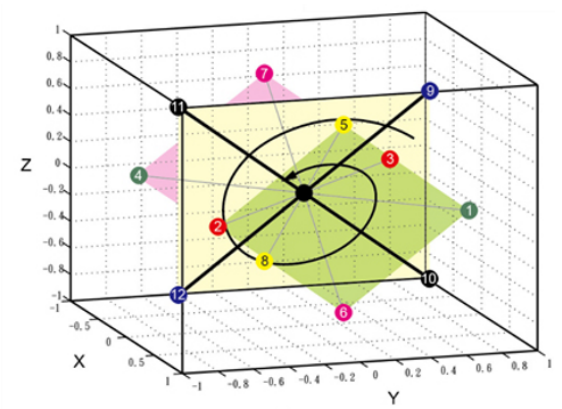

(c)

Figure 4 Square-Based Rotation: 3 ways to partition the 12 neighbours of the central point into 3 squares 
different partitionings of the 12 neighbours into 3 squares. For each partitioning, we rotate each square synchronously. The rotation axis is the line defined by the centres of the 3 squares, and the rotation angle is one of $90^{\circ}, 180^{\circ}$ or $270^{\circ}$. We thus can define 9 different square-based rotations.

In triangle-hexagon-based rotation, the 12 neighbours of a lattice point are partitioned into two triangles and one hexagon. Figure 5 shows 4 different partitionings for triangle-hexagon-based rotation. The rotation axis is the line defined by the centres of the two triangles and the hexagon, and the rotation angle is $120^{\circ}$ or $240^{\circ}$. Thus 8 different triangle-hexagon-based rotations are defined.

Note that, for each above-mentioned rotation, the representation of a rotated conformation can be computed from its original conformation by label permutation. Figure 6 gives an illustration of square-based rotations and their corresponding label permutations. In Figure 6(a) and 6(b) give the parent conformations. Figure 6(c) gives the offspring without rotation. Figure 6(d) shows the 3 squares in the partitioning of neighbours. Figure 6(e) gives the corresponding label permutations for rotation angles $90^{\circ}, 180^{\circ}$ and $270^{\circ}$ respectively. Figure 6 (f) gives the 4 offspring with the part in red rotated $0^{\circ}$, $90^{\circ}, 180^{\circ}$ and $270^{\circ}$ respectively. Note that the label sequence of the conformation of the red part for each rotation angle is $(1,1,6,4)$ for $0^{\circ},(3,3,10,2)$ for $90^{\circ},(4,4,8,1)$ for $180^{\circ}$ and $(2,2,12,3)$ for $270^{\circ}$. Each rotated conformation is computed by its corresponding label permutation in Figure 6(e). An illustration of triangle-hexagon-based rotation is given in Figure 6(g), 6(i) and 6(j).

\section{Generalized pull move}

Pull Move was first proposed by Lesh et al., [12] and used as local search on the $2 \mathrm{D}$ square HP protein

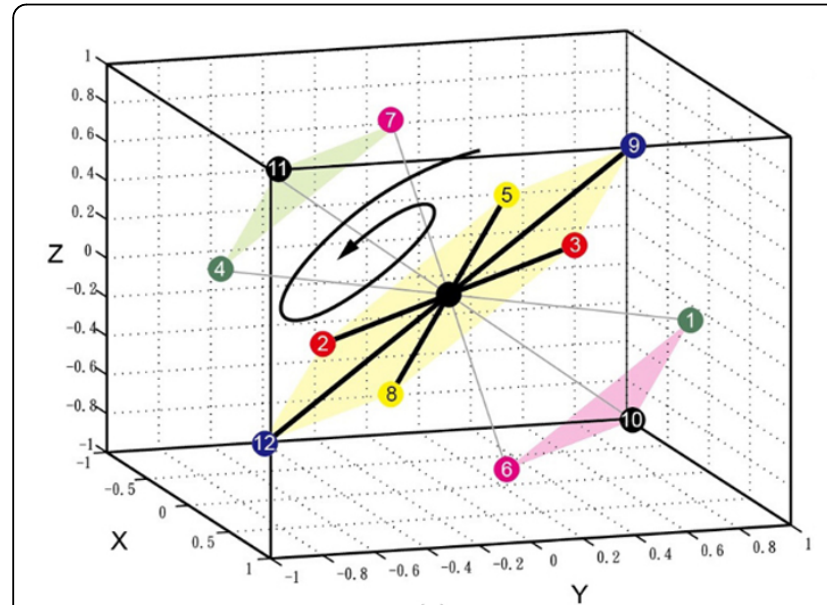

(a)

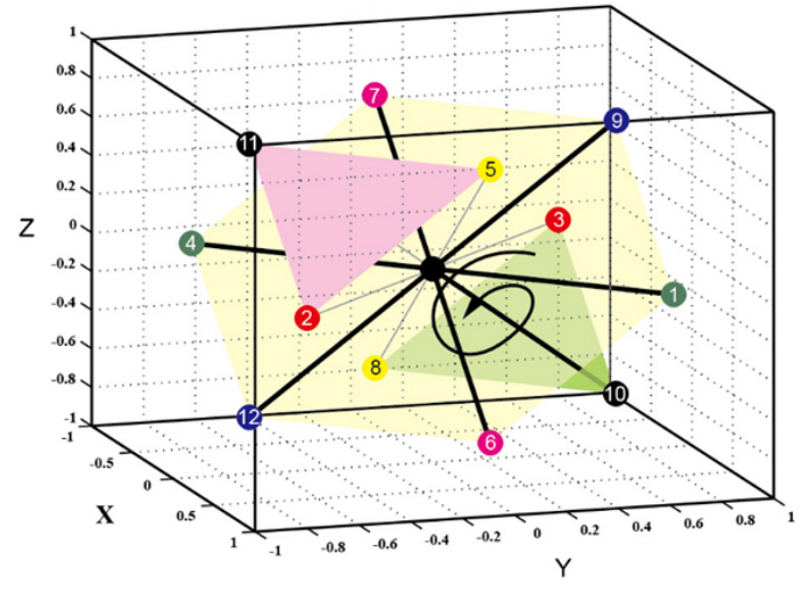

(c)

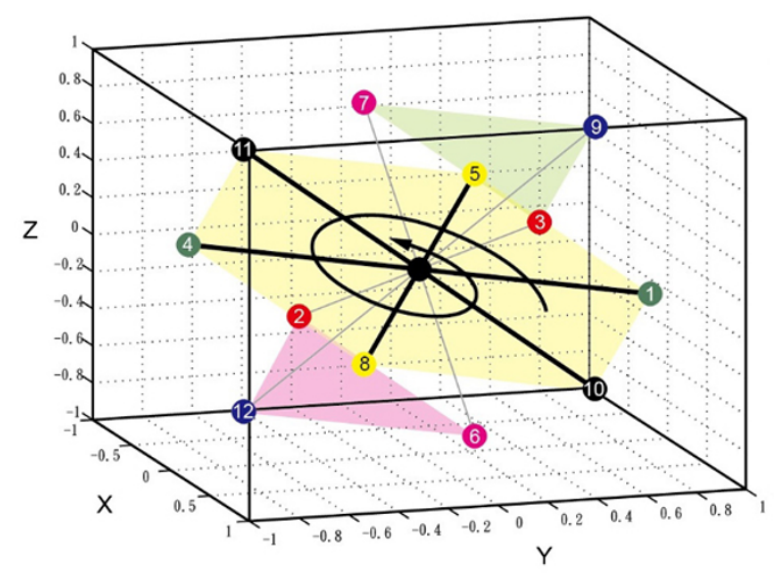

(b)

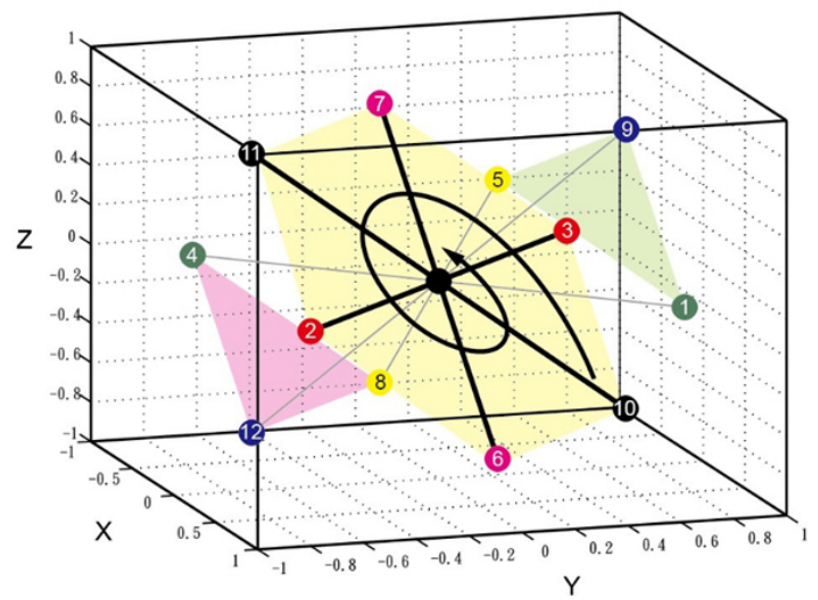

(d)

Figure 5 Triangle-Hexagon-Based Rotations. Triangle-Hexagon-Based Rotations: 4 ways to partition the 12 neighbours of the central point into two triangles and one hexagon. 


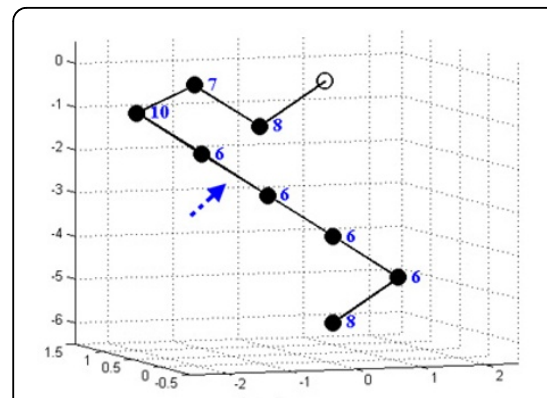

( a )

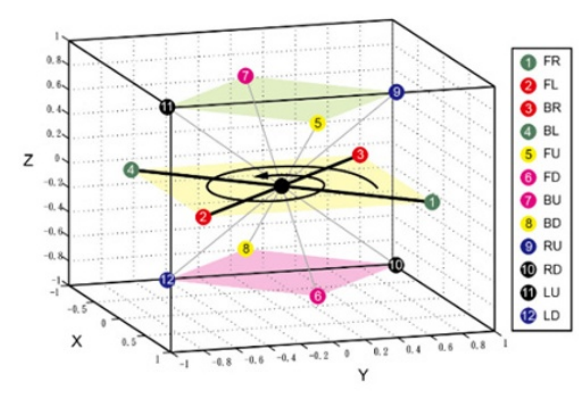

(d)

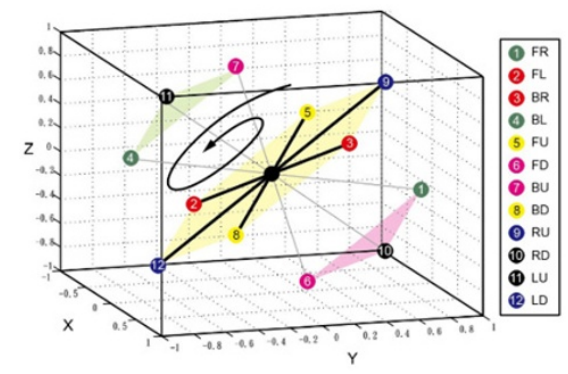

( g)

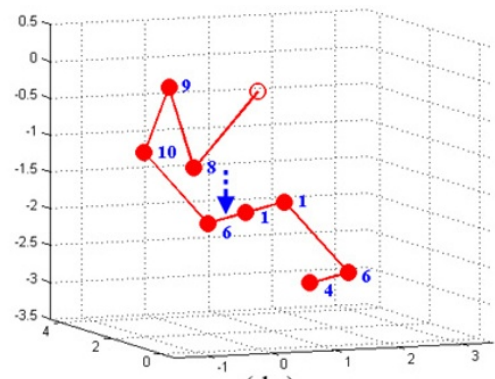

(b)

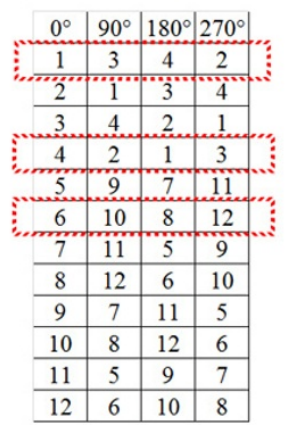

(e)

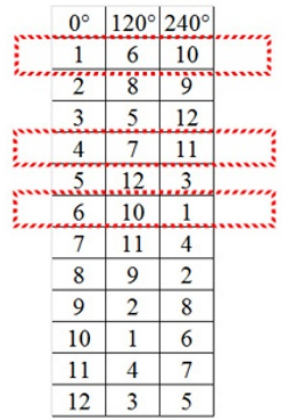

( h )

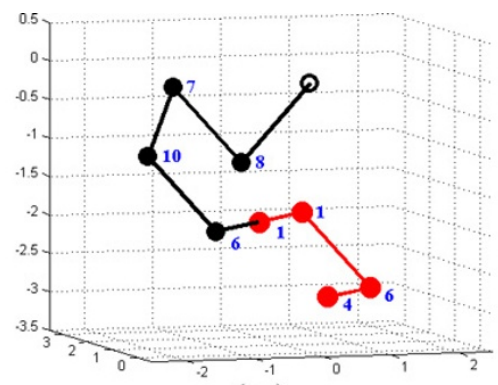

(c)

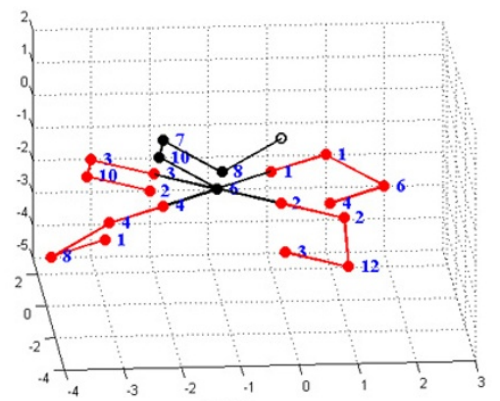

( f)

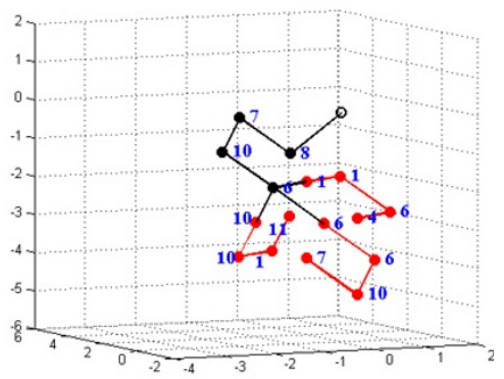

(i)

Figure 6 Rotation-based crossover operate. Illustration of rotation-based crossover: (a) and (b) are the parent conformations; (c) is the offspring without rotation; (d) shows the 3 squares in one partitioning of neighbours; (e) shows the corresponding label permutation for rotation angle $90^{\circ}, 180^{\circ}$ and $270^{\circ}$; (f) shows the 4 offspring with the part in red rotated $0^{\circ}, 90^{\circ}, 180^{\circ}$ and $270^{\circ}$; (g), (i) and (j) illustrate trianglehexagon-based rotation.

folding problem. Böckenhauer et al., [15] further applied Pull Move in 2D triangular and 3D FCC lattice models and demonstrated that this method is reciprocal and complete.

In Pull Move, the next point is pulled to the original position of its previous point. In this paper, we propose a Generalized Pull Move (GPM) in which a point is not restricted to being moved to the position of its previous point; instead it can be moved to any common neighbour of the new position of its previous point and its current position. We thus can have multiple choices to move the next point. Figure 7 gives an illustration of GPM on 2D FCC. Figure 7(a) shows the only result obtained by Pull Move, and Figure 7(b)-(e) demonstrates the 4 possible results obtained by GPM. It is noted that in GPM, after the $i$ th point is moved, there are 2 possible positions to move the $(i+1)$ th point to as there are 2 common neighbours between the new position of the $i$ th point and the original position of the $(i+1)$ th point. On 3D FCC, the number of possible positions to move to the next point is 4 .

When GPM initiates, if the number of possible choices to move the next point to is greater than one, then a random choice is made. If the free energy of the newly pull-moved conformation is lower than the original conformation, the new conformation will replace the 


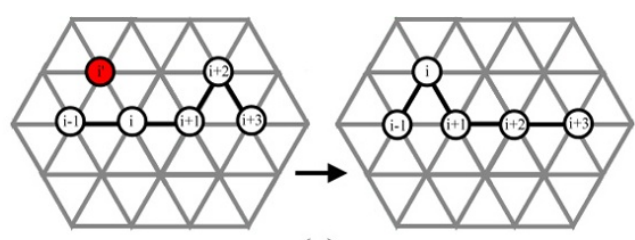

(a)

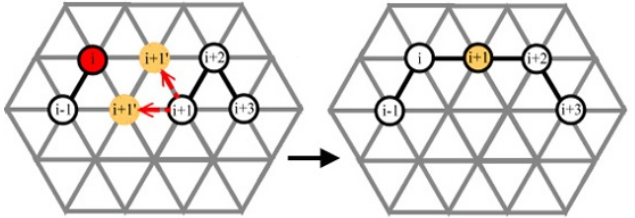

(b)

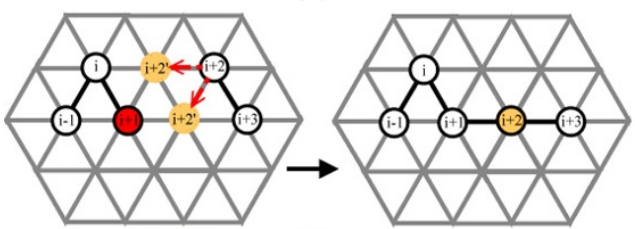

(c)

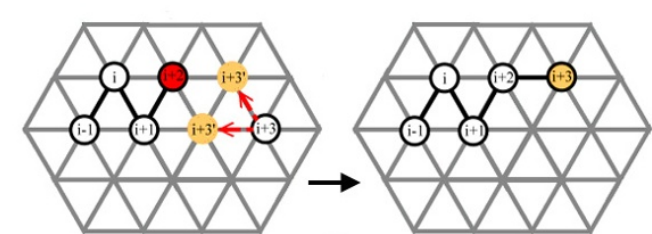

(d)

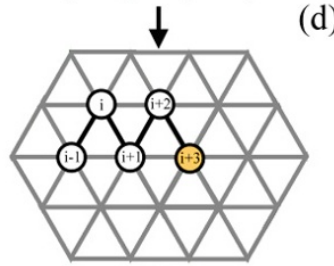

(e)

Figure 7 Generalized Pull Move. Generalized Pull Move on 3D FCC lattice: (a) shows the result obtained by the traditional Pull Move; (b) to (e) shows the 4 possible results obtained by Generalized Pull Move.

original conformation. Otherwise, the original conformation will remain unchanged.

\section{K-site-move-based mutation}

Monomer or dimer moves were often used in past research as methods for local search. In this paper, we apply K-site move to enhance mutation to search the best conformation obtained by moving $K$ consecutive points in the conformation.

However, the searching space increases exponentially with the increase of $\mathrm{K}$ because the number of possible SAWs in a $3 \mathrm{D}$ FCC lattice is given by $S A W_{F C C}=$ $1.26 K^{0.16}(10.0364)^{K}[44]$. In the implementation, a lower bounding technique is applied to reduce the search space. In particular, for each search path, a lower bound, which is defined as the sum of the path length and the Euclidean distance between its end point of the path and the destination point, is estimated and the path is pruned in the search process if the estimated lower bound is larger than $\mathrm{K}+1$. Note that a small value of $\mathrm{K}$ may limit the search space and degrade the effectiveness of the search process. On the other hand, a large value of $\mathrm{K}$ can enlarge the search space but, at the same time, increase the search time exponentially. The value of $K$ is set as 3 in this paper.

\section{Survivor selection}

After generating a set of offspring, only the top fittest chromosomes are selected to survive into the next generation.

\section{Termination}

The process is repeated a fixed iteration size of times. When terminated, the best conformation remaining in the population is returned.

\section{Experimental results}

To evaluate the effectiveness of our approach, experiments over 4 data sets were carried out, including two sets of short amino acids HP-sequences with lengths from 20 to 64, and two sets of longer amino acids HP-sequences with lengths from 90 to 200 . Tables $1,2,3$ and 4 summarize amino acids HP-sequences of the 4 data sets.

\section{Experiment over data set I}

Data set I consists of eight peptides of 20-64 amino acids which have been widely used in previous research $[13-18,20,25,26]$. In this experiment, we set the crossover rate and mutation rate to be 0.85 and 0.4 , respectively. The population size is 10 . The iteration size is 30 for sequence 1-5, 100 for sequence 6-7, and 150 for sequence 8 . Table 5 compares our results with the results reported by several previous approaches, including ETS [15] which is proposed by Böckenhauer et al., [15] to integrate Tabu search, HGA which is a hybrid genetic algorithm proposed by Hoque et al. [22], and MA $[18,26]$ which is a memtic algorithm on 2D triangular lattice and extended to 3D FCC in this study. The results show that both our approach and ETS find optimal conformations for all sequences in this data set and achieve the best performance. 
Table 1 Data Set I: a group of eight HP sequences with 20-64 amino acids.

\begin{tabular}{|c|c|c|}
\hline Seq. & Len. & Protein Sequence \\
\hline S1 & 20 & HPHPPHHPHPPHPHНPPHPH \\
\hline S2 & 24 & НHРPHРPHРPHРPHРPHРPHРPHН \\
\hline S3 & 25 & РРНРРННРРРРННРРРРННРРРРНН \\
\hline S4 & 36 & РРРННРРННРРРРРНННННННРРННРРРРННРРНРР \\
\hline S5 & 48 & 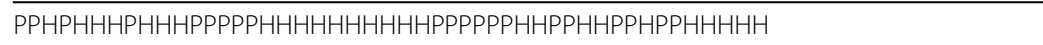 \\
\hline S6 & 50 & ННРНРНРНРННННРНРРPНРРРНРРРРНРРРНРРРНРННННРНРНРНРНН \\
\hline S7 & 60 & 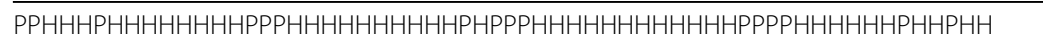 \\
\hline S8 & 64 & ННННННННННННРНРНРРННРРННРРНРРННРРННРРНРРННРРННРРНРНРНННННННННННН \\
\hline
\end{tabular}

\section{Experiment over data set II}

Data set II consists of ten peptides of 48 amino acids each. This set of sequences has been a classical benchmark used on the 3D cube lattice model and it was used on 3D FCC lattice recently by Dotu et al. [28]. In this experiment the population size is 40 and the iteration size is 150 . The crossover rate and mutation rate are 0.85 and 0.4 respectively. The result is given in Table 6. We compare our approach and several approaches proposed by Dotu et al., [28] which combine Tabu search, constraint programming and large neighbor search (LNS). In Table 6, LS denotes Tabu Search with random initialization, LS-G denotes Tabu Search combined with constraint programming, LS-2N denotes2-Neighborhood Tabu Search with random initialization, LS-2N-G denotes2-Neighborhoods Tabu Search combined with constraint programming, LNSMULT denotes Multiple Sequence Reoptimized LNS, and LNS-3D denotes 3D Structure Reoptimized LNS [28]. The results show that only our approach and LNS-MULT can find optimal conformations for all sequences in this data set.

\section{Experiment over data set III and IV}

Data set III consists of 15 sequences of length 90-200 which are used in Dotu et al. [28]. To our knowledge, no EA-based approaches have been reported for sequences of such length. We compare our approach with the LNS-based [28] and HPstruct [23,24]. It should be pointed out that HPstruct by Will [27] is a sofware tool for the protein structure prediction on the HP lattice model which implements the constraint programming and hydrophobic threading algorithm developed by Backofen and Will [27]. Table 7 summarizes the results. HPstruct finds optimal conformations and outperforms our method, provided that HPstruct converges. However, for sequence F180_1 and F180_2, HPstruct does not return any conformation. As noted in [28] and experienced in our experioment, HPstruct is limited by pre-computed $\mathrm{H}$-cores, and no conformation will be returned if it fails to converge. Our method is able to find conformations for these 2 sequences with energy lower than those obtained by LNS-based approaches [28], including LNS-MULT and LNS-3D which perform better than our approach for the first 12 sequences, but worse for the last 3 sequences.

In the comparison, our approach performs best for sequence F180_1 and F180_2. Figure 8 gives the conformations returned by our approach for sequences F180_1, F180_2 and F180_3.

We further submit 5 sequences in data set IV, which are selected from PDB with the ID: $4 B P 2,2 A A S, 5 L Y Z$,

Table 2 Data Set II

\begin{tabular}{|c|c|c|}
\hline Seq. & Len. & Protein Sequence \\
\hline$\overline{\mathrm{H} 1}$ & & НРННРРННННРНННРРННРРНРНННРНРННРРННРРРНРРРРРРРРРНН \\
\hline $\mathrm{H} 2$ & & ННННРННРНННННРРНРРННРРНРРРРРРНРРНРРРНРРННРРНННРН \\
\hline $\mathrm{H3}$ & & РНРННРННННННРРНРНРРНРННРНРНРРРНРРННРРННРРНРНРРНР \\
\hline $\mathrm{H} 4$ & & РНРННРРНРНННРРННРННРРРНННННРРНРННРНРНРРРРНРРНРНР \\
\hline $\mathrm{H} 5$ & 48 & РРНРРРНРННННРРННННРННРНННРРНРНРНРРНРРРРРРННРННРН \\
\hline H6 & & НННРРРННРНРННРННРННРНРРРРРРРНРНРРНРРРНРРННННННРН \\
\hline $\mathrm{H7}$ & & РНРРРРНРНННРНРННННРННРННРРРНРНРРРНННРРННРРННРРРН \\
\hline H8 & & РННРНННРННННРРНННРРРРРРНРННРРННРНРРРННРНРНРННРРР \\
\hline H9 & & РНРНРРРРНРНРНРРНРННННННРРНННРНРРНРННРРНРНННРРРРН \\
\hline $\mathrm{H} 10$ & & РННРРРРРРННРРРНННРНРРНРННРРНРРНРРННРРНННННННРРНН \\
\hline
\end{tabular}


Table 3 Data Set III

\begin{tabular}{|c|c|c|}
\hline Seq. & Len. & Sequences \\
\hline F90_1 & 90 & 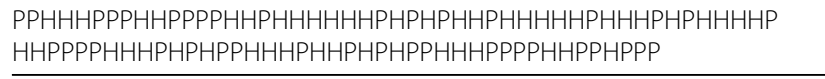 \\
\hline F90_2 & 90 & 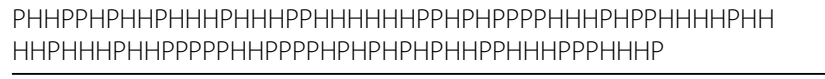 \\
\hline F90_3 & 90 & 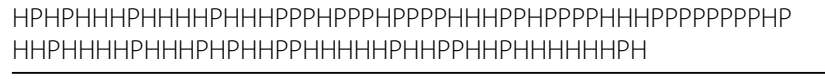 \\
\hline F90_4 & 90 & 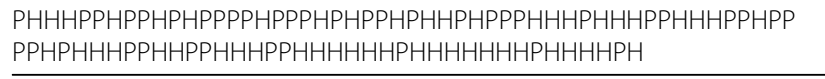 \\
\hline F90_5 & 90 & 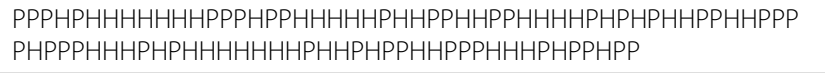 \\
\hline S1 & 135 & 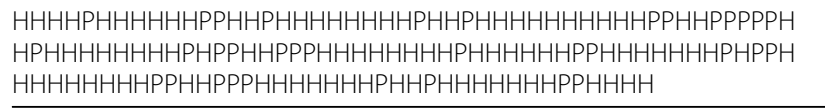 \\
\hline S2 & 151 & 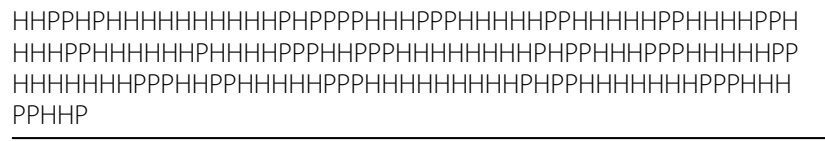 \\
\hline S3 & 162 & 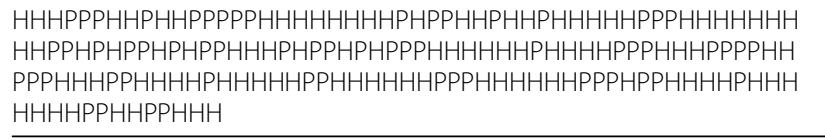 \\
\hline S4 & 164 & 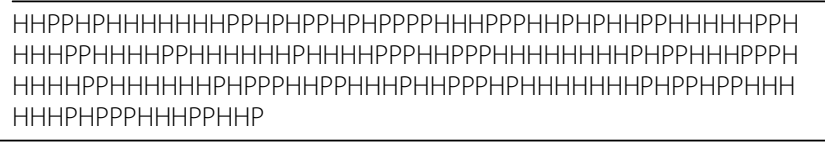 \\
\hline R1 & 200 & 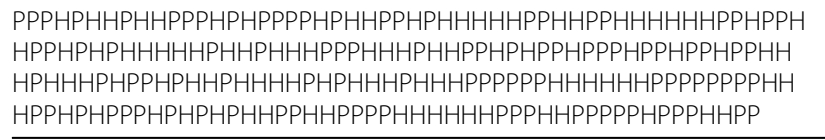 \\
\hline R2 & 200 & 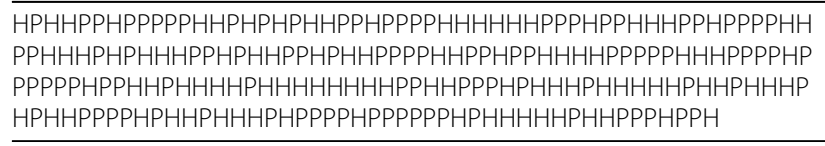 \\
\hline R3 & 200 & 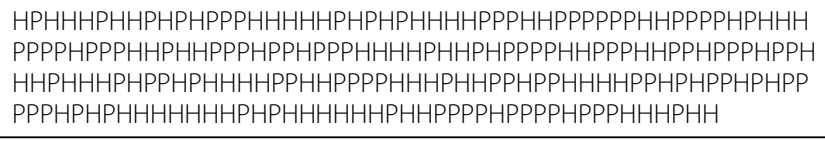 \\
\hline$\overline{F 180 \_1}$ & 180 & 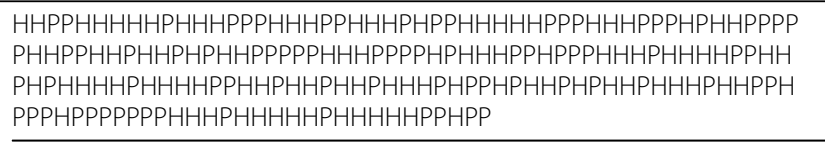 \\
\hline F180_2 & 180 & 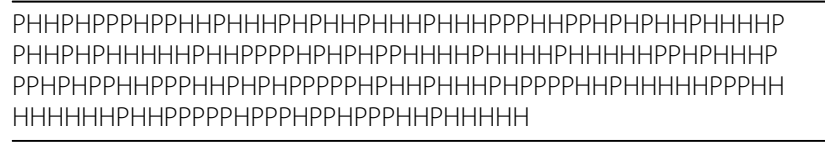 \\
\hline F180_3 & 180 & 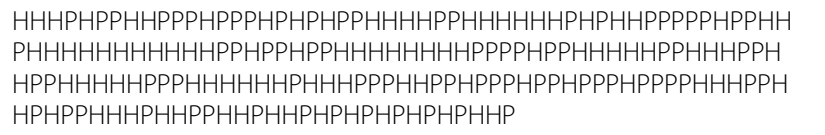 \\
\hline
\end{tabular}

9WGA, and 1RBP, and used in [45] to study the effect of disulfide bonds in protein structure prediction. HPstruct fails to return any conformation for all 5 sequences. Figure 9 shows the conformations by our approach. The results for data sets III and IV suggest that, although HPstruct performs the best, our approach is more robust than HPstruct and can be used as complemenntary to HPstruct, especially when it fails to converge. In this case, our approach may perform better than the LNS-based approach as shown in the experiments for sequences F180_1 and F180_2. 
Table 4 Data Set IV: the amino acid sequences and the corresponding HP sequences.

\begin{tabular}{|c|c|c|}
\hline PDB ID. & Len. & Sequences (original and HP transform) \\
\hline \multirow[t]{2}{*}{$\overline{4 B P 2}$} & 123 & $\begin{array}{l}\text { ALWQFNGMIKCKIPSSEPLLDFNNYGCYCGLGGSGTPVDDLDRCCQTH } \\
\text { DNCYKQAKKLDSCKVLVDNPYTNNYSYSCSNNEITCSSENNACEAFIC } \\
\text { NCDRNAAICFSKVPYNKEHKNLDKKNC }\end{array}$ \\
\hline & & 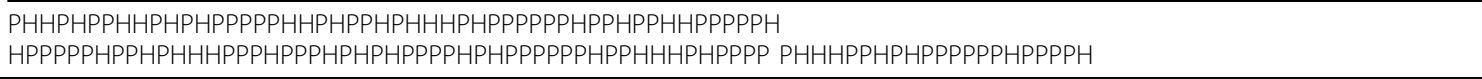 \\
\hline \multirow[t]{2}{*}{ 2AAS } & 124 & $\begin{array}{l}\text { KETAAAKFERQHMDSSTSAASSSNYCNQMMKSRNLTKDRCKPVNTFVH } \\
\text { ESLADVQAVCSQKNVACKNGQTNCYQSYSTMSITDCRETGSSKYPNCAY } \\
\text { KTTQANKHIIVACEGNPYVPVHFDASV }\end{array}$ \\
\hline & & 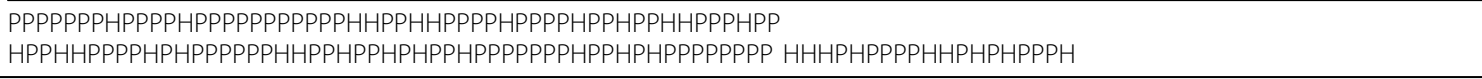 \\
\hline \multirow[t]{2}{*}{$5 L Y Z$} & 129 & $\begin{array}{l}\text { KVFGRCELAAAMKRHGLDNYRGYSLGNWVCAAKFESNFNTQATNRNT } \\
\text { DGSTDYGILQINSRWWCNDGRTPGSRNLCNIPCSALLSSDITASVNCAKK } \\
\text { IVSDGNGMNAWVAWRNRCKGTDVQAWIRGCRL }\end{array}$ \\
\hline & & 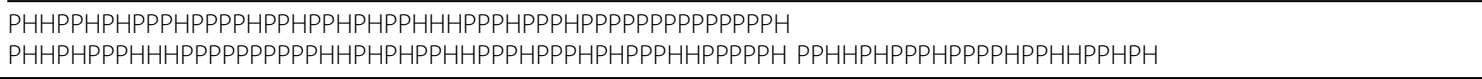 \\
\hline \multirow[t]{2}{*}{$9 W G A$} & 170 & $\begin{array}{l}\text { RCGEQGSNMECPNNLCCSQYGYCGMGGDYCGKGCQNGACWTSKRCGS } \\
\text { QAGGATCPNNHCCSQYGHCGFGAEYCGAGCQGGPCRADIKCGSQSGGK LCPNNLCCSQWGFCGLGSEFCGGGCQSGACSTDKPCGKDAGGRVCTNN } \\
\text { YCCSKWGSCGIGPGYCGAGCQSGGCDA }\end{array}$ \\
\hline & & 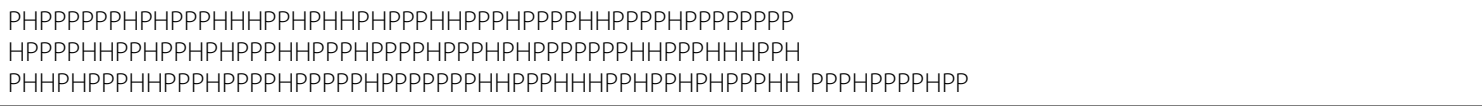 \\
\hline \multirow[t]{2}{*}{ 1RBP } & 174 & $\begin{array}{l}\text { ERDCRVSSFRVKENFDKARFSGTWYAMAKKDPEGLFLQDNIVAEFSVDE } \\
\text { TGQMSATAKGRVRLLNNWDVCADMVGTFTDTEDPAKFKMKYWGVASF LQKGNDDHWIVDTDYDTYAVQYSCRLLNLDGTCADSYSFVFSRDPNGLP } \\
\text { PEAQKIVRQRQEELCLARQYRLIVHNGYC }\end{array}$ \\
\hline & & 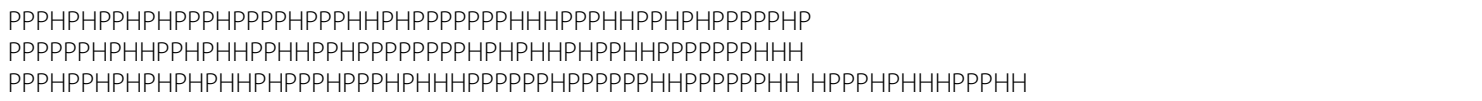 \\
\hline
\end{tabular}

Table 5 Result for Data Set I and Comparison with ETS, HGA, and MA.

\begin{tabular}{ccccccc}
\hline Seq. & Native E (HPstruct) & Len & ETS[15] & HGA[22] & MA[26] & Our Method \\
\hline S1 & $\mathbf{2 3}$ & 20 & $\mathbf{2 3}$ & 29 & $\mathbf{2 3}(22.53)$ & $\mathbf{2 3}(22.30)$ \\
S2 & $\mathbf{2 3}$ & 24 & $\mathbf{2 3}$ & 28 & $\mathbf{2 3} .63)$ & $\mathbf{2 3}(22.10)$ \\
S3 & $\mathbf{1 7}$ & 25 & $\mathbf{1 7}$ & 25 & $\mathbf{1 7}(17.00)$ & $\mathbf{1 7}(17.00)$ \\
S4 & $\mathbf{3 8}$ & 36 & $\mathbf{3 8}$ & 50 & $\mathbf{3 8}(36.70)$ & $\mathbf{3 8}(36.57)$ \\
S5 & $\mathbf{7 4}$ & 48 & $\mathbf{7 4}$ & 65 & $72(68.50)$ & $\mathbf{7 4}(71.70)$ \\
S6 & $\mathbf{7 3}$ & 50 & - & $59(62.73)$ & $\mathbf{7 3}(66.60)$ \\
S7 & $\mathbf{1 3 0}$ & 60 & $\mathbf{1 3 0}$ & 114 & $122(115.87)$ & $\mathbf{1 3 0}(124.80)$ \\
S8 & $\mathbf{1 3 2}$ & 64 & $\mathbf{1 3 2}$ & 98 & $115(107.00)$ & $\mathbf{1 3 2}(126.40)$ \\
\hline
\end{tabular}

Table 6 Result for Data Set II and Comparison with LNS-based approaches [28].

\begin{tabular}{|c|c|c|c|c|c|c|c|c|c|}
\hline Seq. & Native E (HPstruct) & Len & LS & LS-G & LS-2N & LS-2N-G & LNS-MULT & LNS-3D & Our Method \\
\hline $\mathrm{H} 1$ & 69 & 48 & $65(57.50)$ & $51(47.17)$ & $68(64.70)$ & $68(64.61)$ & $69(66.77)$ & $69(67.68)$ & $69(67.37)$ \\
\hline $\mathrm{H} 2$ & 69 & 48 & $64(56.59)$ & $55(46.79)$ & $69(64.32)$ & $68(62.51)$ & $69(66.60)$ & $69(66.73)$ & $69(66.97)$ \\
\hline $\mathrm{H} 3$ & 72 & 48 & $66(56.69)$ & $58(54.38)$ & $68(62.08)$ & $67(62.51)$ & $72(68.02)$ & $71(68.06)$ & $72(68.80)$ \\
\hline $\mathrm{H} 4$ & 71 & 48 & $65(58.08)$ & $56(49.26)$ & $67(63.15)$ & $68(63.10)$ & $71(67.31)$ & $71(67.61)$ & $71(68.10)$ \\
\hline $\mathrm{H} 5$ & 70 & 48 & $64(57.01)$ & $57(42.95)$ & $67(63.38)$ & $68(63.79)$ & $70(66.98)$ & $70(67.04)$ & $70(67.77)$ \\
\hline $\mathrm{H} 6$ & 70 & 48 & $63(56.52)$ & $40(34.35)$ & $69(63.38)$ & $68(64.91)$ & $70(67.49)$ & $70(67.43)$ & $70(66.93)$ \\
\hline $\mathrm{H} 7$ & 70 & 48 & $63(58.15)$ & $49(41.10)$ & $68(63.36)$ & $67(63.75)$ & $70(66.55)$ & $69(66.68)$ & $70(67.57)$ \\
\hline $\mathrm{H} 8$ & 69 & 48 & $63(55.31)$ & $54(50.27)$ & $67(62.20)$ & $66(62.56)$ & $69(65.80)$ & $69(65.81)$ & $69(66.37)$ \\
\hline $\mathrm{H} 9$ & 71 & 48 & $67(58.91)$ & $54(46.77)$ & $69(64.90)$ & $69(64.40)$ & 71 (67.95) & 71 (67.92) & 71 (69.10) \\
\hline $\mathrm{H} 10$ & 68 & 48 & $64(57.47)$ & $45(30.03)$ & 67 (63.96) & $67(63.61)$ & $68(65.76)$ & $68(65.67)$ & $68(66.47)$ \\
\hline
\end{tabular}


Table 7 Result for Data Set III and Comparison with LNS-based approaches [28].

\begin{tabular}{cccccccccc}
\hline Seq. & Native E HPstruct & Len & LS & LS-G & LS-2N & LS-2N-G & LNS-MULT & LNS-3D & Our Method \\
\hline F90_1 & $\mathbf{1 6 8}$ & 90 & $143(125.75)$ & $104(102.97)$ & $154(142.25)$ & $153(142.77)$ & $164(156.83)$ & $\mathbf{1 6 5}(157.39)$ & $161(151.77)$ \\
F90_2 & $\mathbf{1 6 8}$ & 90 & $142(123.68)$ & $117(112.05)$ & $156(141.45)$ & $157(141.89)$ & $\mathbf{1 6 3}(155.05)$ & $163(155.81)$ & $161(153.77)$ \\
F90_3 & $\mathbf{1 6 7}$ & 90 & $138(121.80)$ & $110(101.70)$ & $157(143.79)$ & $159(145.24)$ & $163(156.23)$ & $163(157.20)$ & $\mathbf{1 6 4}(153.13)$ \\
F90_4 & $\mathbf{1 6 8}$ & 90 & $144(124.35)$ & $94(92.74)$ & $162(144.17)$ & $158(139.26)$ & $\mathbf{1 6 4}(156.20)$ & $163(156.54)$ & $159(152.67)$ \\
F90_5 & $\mathbf{1 6 7}$ & 90 & $138(121.59)$ & $110(107.65)$ & $157(143.32)$ & $154(145.00)$ & $163(155.77)$ & $\mathbf{1 6 4}(157.46)$ & $160(152.60)$ \\
\hline S1 & $\mathbf{3 5 7}$ & 135 & $296(271.03)$ & $276(270.99)$ & $343(320.55)$ & $345(323.81)$ & $349(332.37)$ & $\mathbf{3 5 1}(336.74)$ & $330(311.53)$ \\
S2 & $\mathbf{3 6 0}$ & 151 & $304(268.43)$ & $250(244.23)$ & $339(318.30)$ & $339(316.60)$ & $349(328.98)$ & $\mathbf{3 5 3}(334.17)$ & $325(303.80)$ \\
S3 & $\mathbf{3 6 7}$ & 162 & $293(259.55)$ & $234(228.71)$ & $332(310.02)$ & $337(306.03)$ & $351(323.77)$ & $\mathbf{3 5 3}(329.80)$ & $324(299.33)$ \\
S4 & $\mathbf{3 7 0}$ & 164 & $294(263.73)$ & $226(222.99)$ & $337(307.77)$ & $329(300.92)$ & $346(323.98)$ & $\mathbf{3 5 4}(334.22)$ & $325(300.50)$ \\
\hline R1 & $\mathbf{3 8 4}$ & 200 & $287(240.85)$ & $212(205.58)$ & $292(254.69)$ & $291(264.53)$ & $313(287.98)$ & $\mathbf{3 3 0}(305.54)$ & $302(283.90)$ \\
R2 & $\mathbf{3 8 3}$ & 200 & $290(239.12)$ & $209(205.60)$ & $294(262.74)$ & $296(267.75)$ & $331(289.83)$ & $\mathbf{3 3 3}(308.31)$ & $299(284.30)$ \\
R3 & $\mathbf{3 8 5}$ & 200 & $260(230.57)$ & $228(212.12)$ & $305(260.70)$ & $299(267.05)$ & $325(288.49)$ & $\mathbf{3 3 4}(307.76)$ & $302(284.60)$ \\
\hline F180_1 & $\mathbf{P}$ & 180 & $244(204.28)$ & $201(188.06)$ & $261(232.30)$ & $265(240.88)$ & $289(264.06)$ & $293(269.07)$ & $\mathbf{3 2 0}(288.41)$ \\
F180_2 & $\mathbf{P}$ & 180 & $240(222.40)$ & $228(211.07)$ & $279(255.24)$ & $278(254.11)$ & $302(280.84)$ & $312(287.21)$ & $\mathbf{3 2 1}(295.50)$ \\
F180_3 & $\mathbf{3 7 8}$ & 180 & $256(227.69)$ & $195(191.91)$ & $292(262.86)$ & $287(261.55)$ & $306(286.78)$ & $313(295.31)$ & $\mathbf{3 1 6}(294.67)$ \\
\hline
\end{tabular}

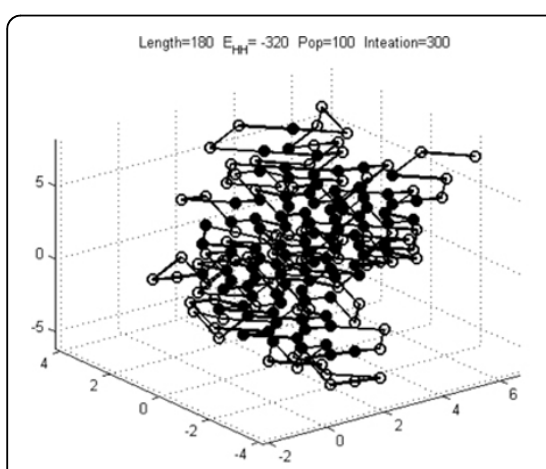

(a)

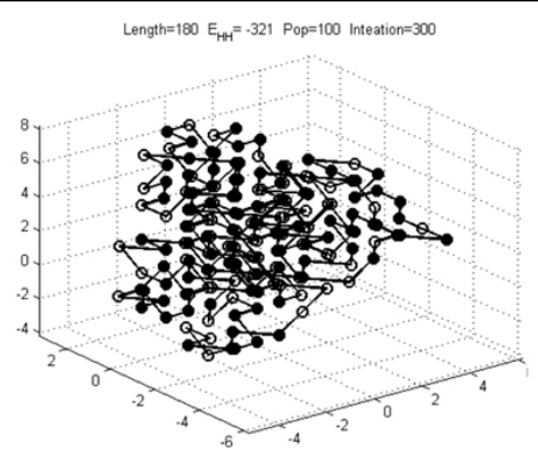

(b)

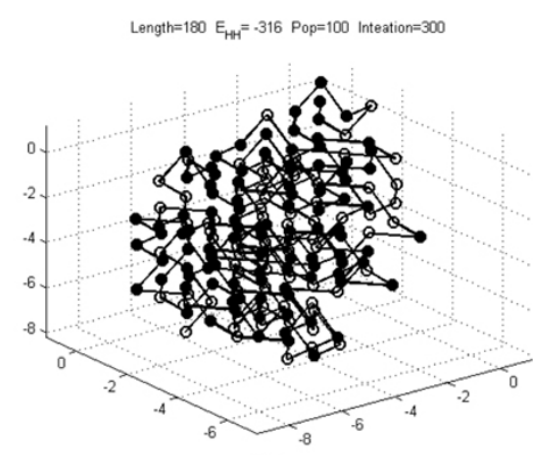

(c)

Figure 8 Configurations for F180_1, F180_2 and F180_3 obtained by our approach

\section{Conclusions}

In this paper an effective EA-based approach for protein folding is presented; the geometry of the 3D FCC lattice has been investigated and several rotations to enhance crossover have been identified. The well-known Pull Move has been generalized, and a lowering bound method has been developed to reduce the search space of $\mathrm{K}$-site move which is used for mutation. It is shown that the combination of rotation, generalized Pull Move and $\mathrm{K}$-site move can enhance the search performance of traditional EA-based approaches. The approach presented is purely EA-based; it does not rely on any optimization library, can be modified to work with any fitness function, and can be easily integrated with Monte Carlo and Tabu searches. Experiments were carried out over several data sets. Although the results show that HPstruct, which is based on constraint programming, performs better than our approach, provided that HPstruct converges, it failed to converge for several sequences in our experiment. Our approach can be used as complementary to HPstruct, especially when HPstruct fails to converge. In the future, further work can be focussed on experiments to improve the search capability of our algorithm for more data sets, especially for long sequences, as well as for more tedious fitness functions such as 20 amino acid pairwise interaction energy functions. In addition, future work will include the combination of more information, such as disulfide bonds and secondary structures which can be effectively predicted from primary sequences in the search process to find structures which are closer to real native structures. 


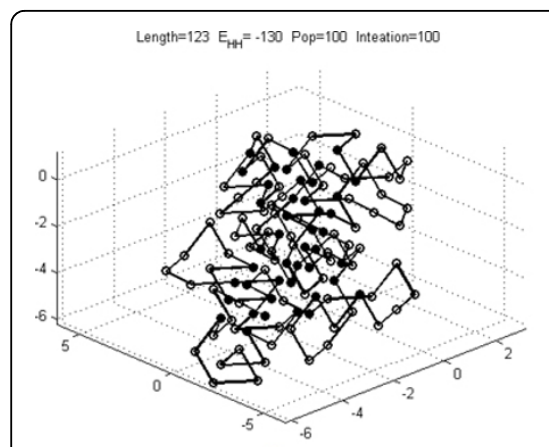

(a)

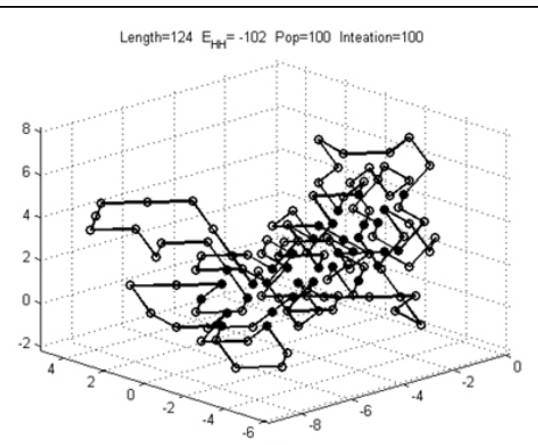

(b)

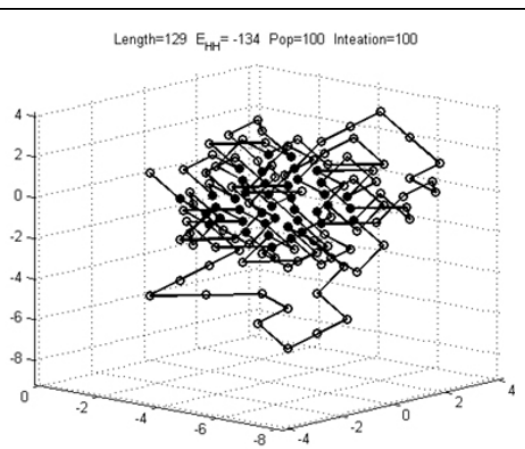

Length $=174 \quad E_{\mathrm{HH}}=-177$ Pop=100 Inteation=100

(c)
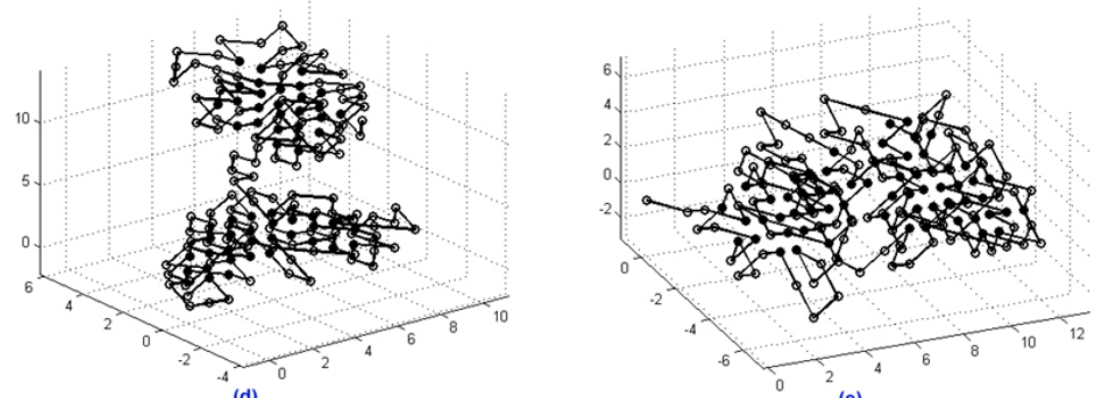

(e)

Figure 9 Configurations for sequences in Data Set IV obtained by our approach

\section{Competing interests}

The authors declare that they have no competing interests.

\section{Authors' contributions}

$J J$ proposed the study of lattice rotation and participated in designing the algorithm and writing the manuscript. SC worked out the details, implemented the algorithm, carried out the experiment and drafted the manuscript. Both authors read and approved the final manuscript.

\section{Acknowledgements}

We would like thank Dr. Lihui Wang at Imperial College London for advice on writing the manuscript and Dr. Roy Preece at Oxford Brookes University for proofreading.

\section{Declarations}

The publication costs for this article were funded by the authors. This article has been published as part of Proteome Science Volume 11 Supplement 1, 2013: Selected articles from the IEEE International Conference on Bioinformatics and Biomedicine 2012: Proteome Science. The full contents of the supplement are available online at http://www.proteomesci. com/supplements/11/S1.

\section{Published: 7 November 2013}

\section{References}

1. Hagerman PJ, Jr IT: From sequence to structure to function. Current Opinion in Structural Biology 1996, 6(3):277-280

2. Mirsky AE, Pauling L: On the structure of native, denatured, and coagulated proteins. Proceedings of the National Academy of Sciences of the United States of America 1936, 22(7):439-447.

3. Orengo CA, Todd AE, Thornton JM: From protein structure to function. Current Opinion in Structural Biology 1999, 9(3):374-382.

4. Lau K, Dill K: A lattice statistical mechanics model of the conformation and sequence space of proteins. Macromolecules 1989, 22:3986-3997.

5. Istrail S, Lam F: Combinatorial algorithms for protein folding in lattice models: a survey of mathematical results. Commun Inf Syst 2009, 9(4):303-346.
6. Hoque M, Chetty M, Lewis A, Sattar A: DFS based partial pathways in GA for protein structure prediction. Pattern Recognition in Bioinformatics 2008, 41-53.

7. Hoque MT, Chetty M, Lewis A, Sattar A: Twin removal in genetic algorithms for protein structure prediction using low-resolution model. IEEE/ACM Trans Comput Biol Bioinform 2011, 8(1):234-245.

8. Hoque MT, Chetty M, Lewis A, Sattar A, Avery VM: DFS-generated pathways in GA crossover for protein structure prediction. Neurocomputing 2010, 73(13):2308-2316.

9. Hsieh SY, Lai DW: A new branch and bound method for the protein folding problem in the HP model. IEEE Transactions on NanoBioscience 2011, 10(2):69-75.

10. Huang $C$, Yang $X$, He Z: Protein folding simulations of $2 D$ HP model by the genetic algorithm based on optimal secondary structures. Computational Biology and Chemistry 2010, 34:137-142.

11. Jiang T, Cui $Q$, Shi G, Ma S: Protein folding simulations for the hydrophobic-hydrophilic model by combining tabu search with genetic algorithms. Journal of Chemical Physics 2003, 119:4592-4596.

12. Lesh $N$, Mitzenmacher M, Whitesides S: A complete and effective move set for simplified protein folding. Proceedings of the Seventh Annual International Conference on Research in Computational Molecular Biology; Berlin, Germany 2003, 188-195.

13. Shmygelska $\mathrm{A}, \mathrm{Hoos} \mathrm{HH}$ : An ant colony optimisation algorithm for the $2 \mathrm{D}$ and 3D hydrophobic polar protein folding problem. BMC Bioinformatics 2005, 6:30

14. Unger R, Moult J: Genetic algorithms for protein folding simulations. Journal of Molecular Biology 1993, 231(1):75-81.

15. Böckenhauer HJ, Dayem Ullah A, Kapsokalivas L, Steinhöfel K: A local move set for protein folding in triangular lattice models. Algorithms in Bioinformatics 2008, 5251:369-381, LNCS

16. Hoque $M$, Chetty $M$, Dooley L: A hybrid genetic algorithm for 2D FCC hydrophobic-hydrophilic lattice model to predict protein folding. Advances in Artificial Intelligence, Lecture Notes in Computer Science 2006, 4304:867-876.

17. Su SC, Lin CJ, Ting CK: An effective hybrid of hill climbing and genetic algorithm for 2D triangular protein structure prediction. Proteome Science 2011, 9(Suppl 1):S19. 
18. Tsay JJ, Su SC: A memetic algorithm for protein structure prediction based on 2D triangular lattice model. Bioinformatics Feb.1-4; Algarve, Portugal 2012, 131-136.

19. Lin CJ, Su SC: Protein 3D HP model folding simulation using a hybrid of genetic algorithm and particle swarm optimization. International Journal of Fuzzy Systems 2011, 13(2):140-147.

20. Thachuk $C$, Shmygelska A, Hoos HH: A replica exchange Monte Carlo algorithm for protein folding in the HP model. BMC Bioinformatics 2007, 8:342.

21. Decatur S, Batzoglou S: Protein folding in the hydrophobic-polar model on the 3D triangular lattice. 6th Annual MIT Laboratory for Computer Science Student Workshop on Computing Technologies 1996.

22. Hoque MT, Chetty M, Sattar A: Protein folding prediction in 3D FCC HP lattice model using genetic algorithm. IEEE Congress on Evolutionary Computation: 25-28 Sept. 2007, 4138-4145.

23. Mann M, Smith C, Rabbath M, Edwards M, Will S, Backofen R: CPSP-webtools: a server for 3D lattice protein studies. Bioinformatics 2009, 25(5):676-677.

24. Mann M, Will S, Backofen R: CPSP-tools-exact and complete algorithms for high-throughput 3D lattice protein studies. BMC Bioinformatics 2008, 9:230

25. Su SC, Tsay JJ: Rotation crossover and K-site move mutation for evolutionary protein folding in 3D FCC HP model (preliminary version). IEEE International Conference on Bioinformatics and Biomedicine 2012, 1-4.

26. Tsay JJ, Su SC: Ab initio protein structure prediction based on memetic algorithm and 3D FCC lattice model. IEEE International Conference on Bioinformatics and Biomedicine Workshops 2011, 315-318.

27. Backofen R, Will S: A constraint-based approach to fast and exact structure prediction in three-dimensional protein models. Constraints 2006, 11(1):5-30

28. Dotu I, Cebrian M, Van Hentenryck P, Clote P: On lattice protein structure prediction revisited. IEEE/ACM Trans Comput Biol Bioinform 2011, 8(6):1620-1632.

29. Hart WE, Istrail S: Robust proofs of NP-hardness for protein folding: general lattices and energy potentials. Journal of Computational Biology : a Journal of Computational Molecular Cell Biology 1997, 4(1):1-22.

30. Berger B, Leighton T: Protein folding in the hydrophobic-hydrophilic (HP) model is NP-complete. Journal of Computational Biology : a Journal of Computational Molecular Cell Biology 1998, 5(1):27-40.

31. Crescenzi P, Goldman D, Papadimitriou C, Piccolboni A, Yannakakis M: On the complexity of protein folding. Journal of Computational Biology 1998 5:423-465

32. Custódio FL, Barbosa HJC, Dardenne LE: Full-atom ab initio protein structure prediction with a genetic algorithm using a similarity-based surrogate model. IEEE Congress on Evolutionary Computation 2010, 1-8.

33. Ullah $A D$, Steinhofel $K$ : A hybrid approach to protein folding problem integrating constraint programming with local search. BMC Bioinformatics 2010, 11(Suppl 1):S39.

34. Dill KA, Bromberg S, Yue K, Fiebig KM, Yee DP, Thomas PD, Chan HS: Principles of protein folding-a perspective from simple exact models. Protein Science : a publication of the Protein Society 1995, 4(4):561-602.

35. Verdier PH, Stockmayer WH: Monte Carlo calculations on the dynamics of polymers in dilute solution. The Journal of Chemical Physics 1962, 36(1):227-235

36. Gurler MT, Crabb CC, Dahlin DM, Kovac J: Effect of bead movement rules on the relaxation of cubic lattice models of polymer chains. Macromolecules 1983, 16(3):398-403.

37. Hsu H-P, Mehra V, Nadler W, Grassberger P: Growth-based optimization algorithm for lattice heteropolymers. Physical Review E 2003, 68(2):021113.

38. Sali A, Shakhnovich $E$, Karplus M: Kinetics of protein folding. A lattice model study of the requirements for folding to the native state. Journal of Molecular Biology 1994, 235(5):1614-1636.

39. Mann M, Hamra MA, Steinhöfel K, Backofen R: Constraint-based local move definitions for lattice protein models including side chains. Proceedings of the Fifth Workshop on Constraint Based Methods for Bioinformatics 2009, 51-59.

40. Raghunathan $\mathrm{G}$, Jernigan RL: Ideal architecture of residue packing and its observation in protein structures. Protein Science : a publication of the Protein Society 1997, 6(10):2072-2083.
41. Yue K, Dill KA: Forces of tertiary structural organization in globular proteins. Proceedings of the National Academy of Sciences of the United States of America 1995, 92(1):146-150.

42. Hoque T, Chetty M, Sattar A: Extended HP model for protein structure prediction. Journal of Computational Biology : a journal of Computational Molecular Cell Biology 2009, 16(1):85-103.

43. Ullah $A D$, Kapsokalivas $L$, Mann M, Steinhöfel K: Protein folding simulation by two-stage optimization. Computational Intelligence and Intelligent Systems 2009, 138-145.

44. Schuster P, Stadler PF: Discrete models of biopolymers., In Handbook of Computional Chemistry 2000.

45. Su SC, Tsay JJ: Evolutionary algorithm in hpc model for protein structure prediction. In Proceedings of the 30th Workshop on Combinatorial Mathematics and Computation Theory 2013

\section{doi:10.1186/1477-5956-11-S1-S19}

Cite this article as: Tsay and Su: An effective evolutionary algorithm for protein folding on 3D FCC HP model by lattice rotation and generalized move sets. Proteome Science 2013 11(Suppl 1):S19.

\section{Submit your next manuscript to BioMed Central and take full advantage of:}

- Convenient online submission

- Thorough peer review

- No space constraints or color figure charges

- Immediate publication on acceptance

- Inclusion in PubMed, CAS, Scopus and Google Scholar

- Research which is freely available for redistribution

Submit your manuscript at www.biomedcentral.com/submit
C) Biomed Central 